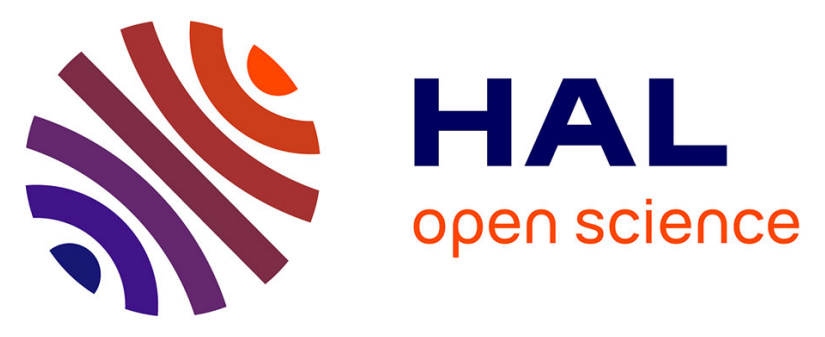

\title{
Arterial Stiffness Assessment by Shear Wave Elastography and Ultrafast Pulse Wave Imaging: Comparison with Reference Techniques in Normotensives and Hypertensives
}

Louise Marais, Mathieu Pernot, Hakim Khettab, Mickael Tanter, Emmanuel Messas, Mustapha Zidi, Stéphane Laurent, Pierre Boutouyrie

\section{To cite this version:}

Louise Marais, Mathieu Pernot, Hakim Khettab, Mickael Tanter, Emmanuel Messas, et al.. Arterial Stiffness Assessment by Shear Wave Elastography and Ultrafast Pulse Wave Imaging: Comparison with Reference Techniques in Normotensives and Hypertensives. Ultrasound in Medicine \& Biology, 2019, 45, pp.758 - 772. 10.1016/j.ultrasmedbio.2018.10.032 . hal-03486877

\section{HAL Id: hal-03486877 https://hal.science/hal-03486877}

Submitted on 20 Dec 2021

HAL is a multi-disciplinary open access archive for the deposit and dissemination of scientific research documents, whether they are published or not. The documents may come from teaching and research institutions in France or abroad, or from public or private research centers.
L'archive ouverte pluridisciplinaire HAL, est destinée au dépôt et à la diffusion de documents scientifiques de niveau recherche, publiés ou non, émanant des établissements d'enseignement et de recherche français ou étrangers, des laboratoires publics ou privés.

\section{(ㄷ)(1) $\$$}

Distributed under a Creative Commons Attribution - NonCommerciall 4.0 International 
1 Arterial stiffness assessment by shear wave elastography and ultrafast pulse wave

2 imaging: comparison with reference techniques in normotensives and hypertensives

3

4 Louise Marais $^{\mathrm{a}, \mathrm{b}}$, Mathieu Pernot ${ }^{\mathrm{c}}$, Hakim Khettab ${ }^{\mathrm{a}}$, Mickael Tanter ${ }^{\mathrm{c}}$, Emmanuel Messas ${ }^{\mathrm{a}}$,

5 Mustapha Zidi ${ }^{\mathrm{b}}$, Stéphane Laurent ${ }^{\mathrm{a}}$, Pierre Boutouyrie ${ }^{\mathrm{a}}$

6

$7{ }^{a}$ Inserm U970, Paris Cardiovascular Research Center (PARCC), Georges Pompidou

8 European Hospital, 56 rue Leblanc, 75015 Paris, France

$9{ }^{\mathrm{b}}$ Bioengineering, Tissue and Neuroplasticity, EA 7377, Paris-Est Créteil University, Faculty

10 of Medicine, Surgical Research Center, 8 rue du Général Sarrail, 94010 Créteil, France

$11{ }^{\mathrm{c}}$ Institut Langevin, ESPCI-ParisTech, PSL Research University, CNRS UMR 7587, Inserm

12 U979, 17 rue Moreau, 75012 Paris, France

13

14 Corresponding author:

15 Louise MARAIS, Inserm U970, 56 rue Leblanc, 75015 PARIS

16 Phone: +33153987967

17 Email: louise.marais@inserm.fr

18 


\section{Abstract (150 words)} elastography, Echotracking, Hypertension 


\section{Introduction}

Arterial stiffness has been shown to be an independent risk factor of cardiovascular (CV) diseases and mortality (Ben-Shlomo et al. 2014; Laurent et al. 2006; Vlachopoulos et al. 2010). Its measurement has been integrated into the European guidelines for the management of arterial hypertension (Mancia et al. 2013). Indeed, arterial stiffness increases with age and hypertension, leading to an increased risk of $\mathrm{CV}$ events such as stroke, myocardial infarction or heart failure. Arterial stiffness can be regarded as a tissue biomarker which integrates the cumulative influence of CV risk factors with time (Laurent et al. 2016). Therefore, early detection of elevated arterial stiffness would enable more accurate risk prediction to better target preventive therapy.

Several indices and methods have been introduced to estimate arterial stiffness noninvasively in vivo at the regional or local level. The measurement of the pulse wave velocity (PWV) is currently regarded as the reference method to assess regional arterial stiffness because of its relative simplicity and reproducibility (Laurent et al. 2006). This technique consists of a direct measurement of the time of propagation of the pulse wave, generated by cardiac ejection, between two sites in the arterial tree, usually the carotid and the femoral arteries. PWV is related to the elastic properties of the arterial wall through the MoensKorteweg equation, used to derive the Young's modulus $E$ of the arterial wall as a function of its thickness $h$, radius $R$, PWV and blood density $\rho$ :

$$
P W V=\sqrt{\frac{E h}{2 R \rho}},
$$

Although widely validated in epidemiology research, the measurement of carotid-tofemoral PWV (cfPWV) suffers from limits due to imprecisions in the distance measurement (Van Bortel et al. 2012), timing algorithms (Millasseau et al. 2005) and complexity due to arterial path and pressure dependency (Fung 1993; Nichols et al. 2011). Therefore, recent efforts have been directed to the measurement of local arterial stiffness, mainly through high- 
resolution ultrasound techniques (Laurent et al. 2016) allowing measurement of distension together with local pulse pressure and calculating distensibility. Indeed, the Bramwell-Hill equation (derived from the Moens-Korteweg equation) relates the PWV to the arterial distensibility Dist, defined as the relative ratio of the change in arterial volume $\mathrm{dV}$ or area $\mathrm{dA}$ (if change in length is neglected) to the change in pressure dP driving the change in volume $(\mathrm{V})$ or area $(\mathrm{A})$ :

$$
\mathrm{PWV}=\sqrt{\frac{1}{\rho \mathrm{Dist}}}=\sqrt{\frac{\mathrm{VdP}}{\rho \mathrm{dV}}} \approx \sqrt{\frac{\mathrm{AdP}}{\rho \mathrm{dA}}}
$$

This method was shown to be of predictive value for CV events (Laurent et al. 2006; van Sloten et al. 2014). When pressure and diameter waveforms are available, this method also allows the construction of the pressure-diameter curve and calculation of arterial stiffness for any given level of blood pressure (BP) (Bussy et al. 2000). With echotracking, we demonstrated that the increase in stiffness of the common carotid artery (CCA) observed in patients with essential hypertension was primarily due to the increased level of $\mathrm{BP}$ and not to hypertension-induced structural modifications of the artery (Bussy et al. 2000; Laurent et al. 1994). However, BP is present in formulas for arterial stiffness calculation (such as equation (2)), which creates intrinsic tautologies when considering the influence of BP and the difference between hypertensive (HT) and normotensive (NT) subjects. Moreover, local BP is estimated through applanation tonometry which has its own limits. This issue highlights the need to develop methods independent of BP in order to clarify the relationship between hypertrophic wall remodelling, increased arterial pressure and arterial stiffness in essential hypertension.

Ultrafast ultrasound imaging is a recent technique which enables the visualization of very short events due to an ultra-high imaging frame rate (up to $10000 \mathrm{~Hz}$ ) allowed by plane wave acquisitions (Tanter et al. 2002). Its ability to measure pulse wave transit time along a short arterial pathway at early and late systole has been demonstrated (Couade et al. 2011; 
Mirault et al. 2015). In addition, this very high frame rate also allows for imaging of the propagation of artificial shear waves generated remotely by an acoustic radiation force (ultrasonic push) (Bercoff et al. 2004). The propagation speed of these extrinsic shear waves is directly related to elastic (shear) modulus of the tissue (Royer and Dieulesaint 2000). Shear wave elastography can be repeated along the cardiac cycle to assess the BP related variations of arterial stiffness (Couade et al. 2010). Shear wave elastography appears as a promising technique to measure arterial stiffness in vivo independently of BP (Messas et al. 2013). However, it has never been tested against reference techniques.

The purpose of the present study was therefore to evaluate the agreement between arterial stiffness measured by shear wave elastography and the reference techniques: local stiffness measured by echotracking and aortic stiffness measured by applanation tonometry. In addition, a secondary aim was to study the variations of arterial stiffness during the cardiac cycle for comparing arterial stiffness in HT patients and NT subjects at similar levels of BP. Finally, the opportunity was also taken to test ultrafast imaging of the natural pulse wave in HT patients.

\section{Materials and methods}

\section{Study population}

This observational case-control study included fifty-six subjects. The HT group consisted of 29 patients aged between 25 and 71 years, equally distributed by sex, with never treated essential hypertension or under antihypertensive treatment but with insufficiently controlled BP. The NT group consisted in 27 age and sex matched healthy volunteers. In both groups, subjects were equally distributed by age group (25-39, 40-54, 55-71 years). HT patients were recruited from the Hypertension and the Pharmacology Units of Georges Pompidou European Hospital (HEGP). Essential hypertension was defined by elevated BP (systolic $\mathrm{BP}[\mathrm{SBP}]>140 \mathrm{mmHg}$ and diastolic $\mathrm{BP}[\mathrm{DBP}]>90 \mathrm{mmHg}$ ) and the verified absence of secondary hypertension. Healthy volunteers were recruited by the Center for 
115 Clinical Investigation of HEGP with a supine SBP $<140 \mathrm{mmHg}$ and DBP $<90 \mathrm{mmHg}$ and no

116 history of cardiovascular disease or additional risk factors. The study was approved by the

117 institutional medical ethics committee of St Germain en Laye hospital and all participants

118 gave informed consent. The study is registered at ClinicalTrials.gov (identifier

119 NCT01743352).

120 Arterial Measurements

121 Investigations were performed in a controlled environment after 10 minutes of

122 recumbent rest. Brachial BP was recorded using an automated oscillometric cuff (Colin BP-

123 880, Colin Medical, TX, USA) every 3 minutes. Right CCA pressure waveform was

124 determined non-invasively via applanation tonometry using the Sphygmocor@ device (AtCor

125 Medical, Australia) (Boutouyrie et al. 1999) and calibrated using DBP and mean BP (MBP)

126 from radial tonometry. cfPWV was also determined via applanation tonometry using the

127 Sphygmocor $@$ device. The intersecting tangent algorithm was used to assess the foot-to-foot

128 transit time. The direct distance between the two sites was determined with a tape measure

129 and corrected by a 0.8 factor according to recommendations (Van Bortel et al. 2012).

130 Right CCA internal diameter, distension and wall intima-media thickness (IMT) were

131 measured using a high-resolution echotracking device (MyLab ${ }^{\mathrm{TM}}$ 70, ART.LAB, Esaote,

132 Italy) consisting of a 128 radio-frequency line multiarray covering a 4-cm arterial segment

133 (Paini et al. 2007). Circumferential wall stress was calculated according to Lamé's equation as

$134 \sigma_{\text {circ }}=$ MBP.d/(2.IMT), where $\mathrm{d}$ is the diastolic internal diameter. Cross-sectional distensibility

135 was calculated as $\operatorname{Dist}=\Delta \mathrm{A} /(\mathrm{A} \cdot \Delta \mathrm{P})$, where $\mathrm{A}$ is the diastolic lumen area, $\Delta \mathrm{A}$ is the stroke

136 change in lumen area and $\Delta \mathrm{P}$ is the carotid pulse pressure (PP), i.e. the difference between

137 SBP and DBP. Incremental elastic modulus was calculated as Einc=[3(1+A/WCSA)]/Dist,

138 where WCSA is the diastolic wall cross-sectional area (Bussy et al. 2000). Local CCA PWV

139 (carPWV) was determined from the distensibility coefficient using equation (2) above. 
Shear wave elastography and ultrafast imaging measurements were performed with the

141 commercial ultrasound scanner Aixplorer ${ }^{\circledR}$ (SuperSonic Imagine, France) equipped with a

142 linear array probe (128 elements, $8 \mathrm{MHz}$, pitch $0.2 \mathrm{~mm}, 28 \mathrm{~mm}$ elevation focus). This system

143 is programmable per channel both in receive (128 channels) and in transmit (256 channels).

144 Plane wave transmit enables the reconstruction of a complete frame from a single

145 transmit/receive event. In this study, images were obtained by applying receive-only dynamic

146 beamforming to backscattered echoes and coherent compounding of three plane waves with

147 different inclinations $\left(-5^{\circ}, 0^{\circ}\right.$ and $5^{\circ}$ ) (Montaldo et al. 2009). The supersonic shear imaging

148 (SSI) technique was used for shear wave elastography measurements (Bercoff et al. 2004).

149 Shear waves were created by a supersonic push which is composed of three consecutive

150 pushes of $100 \mu$ s located at three depths $5 \mathrm{~mm}$ apart along the center line of a region of interest

151 (ROI) manually positioned by the sonographer in order to include the anterior and posterior

152 CCA walls. The propagation of the shear waves was then imaged during $5 \mathrm{~ms}$ with a frame

153 rate of $8000 \mathrm{images} / \mathrm{s}$. A sequence of 8 consecutive supersonic pushes at intervals of $200 \mathrm{~ms}$

154 was triggered on the R-wave peak (maximum) of the ECG. This acquisition sequence was

155 repeated three times for reproducibility assessment. The propagation of the natural pulse wave

156 along the right CCA was imaged in immediate succession with the probe maintained in the

157 same position. A sequence of 1000 images acquired with a frame rate of 2000 images/s was

158 triggered on the R-wave peak through the ECG-coupled imaging system. Measurements were

159 performed three times to assess reproducibility. The in-phase and quadrature (IQ) data were

160 exported, stored and processed a posteriori in a blind manner using MATLAB R2014a (The

161 MathWorks Inc., USA).

162 Shear wave elastography post-processing

163 First, the arterial walls were localized on the IQ images. Because of the high

164 acquisition frame rate $(8000 \mathrm{~Hz})$, the contrast of the images was insufficient to use automatic 165 segmentation and tracking algorithms. Instead we used the standard ultrasound image 
recorded at the beginning of the acquisition sequence to manually determine the anterior and

167 posterior wall position for the first push using three points and a second order polynomial

168 interpolation (Fig. 1a). We assumed that the wall did not move significantly during the $5 \mathrm{~ms}$

169 of imaging following the push so that a tracking operation was not needed. However, the time

170 between two consecutive pushes $(200 \mathrm{~ms})$ was long enough with regard to the cardiac cycle to

171 lead to an important displacement of the walls. To determine the new positions of the walls

172 for the seven subsequent pushes, we used the diameter values measured by echotracking. The

173 mean cycles of CCA diameter measured by echotracking and CCA BP measured by

174 applanation tonometry were aligned temporally (Fig. 1b). The time delay between the R-wave

175 peak of the ECG (trigger for $1^{\text {st }}$ push) and the foot of the pressure wave $\left(\Delta \mathrm{T}_{\mathrm{R} \text {-peak foot }}\right)$ was

176 extracted from the applanation tonometry measurement. It enabled identification of the time

177 point corresponding to the $1^{\text {st }}$ push and the subsequent 7 pushes every $200 \mathrm{~ms}$ (Fig. 1b). As

178 shown in Figure 1c, the contrast of the IQ images was sufficient to evaluate the position of the

179 posterior wall but not the anterior wall. Therefore, the change in position of the posterior wall

180 corresponding to the time points of the different pushes was manually evaluated by

181 comparing the first IQ image of the consecutive pushes. The position of the anterior wall at

182 the time of each push was then automatically determined using the lumen diameter

183 measured by echotracking (Fig. 1c). In order to cover the entire wall thickness and in case

184 of small shifts due to manual positioning, five adjacent position lines covering $1 \mathrm{~mm}$, centred

185 on the previously determined position line, were analysed (Fig. 1c).

186 Secondly, a frame-to-frame IQ cross-correlation algorithm was performed to

187 determine the radial velocity of the whole image (Pernot et al. 2007). The velocity values

188 corresponding to the longitudinal elements of the anterior and posterior walls were extracted

189 to obtain space-time representations of the arterial wall velocities (5 for each wall

190 corresponding to the 5 position lines) (Fig. 1d). These graphs displayed two main diagonal

191 wavefronts corresponding to the propagation of the shear wave in the anterograde and 
retrograde direction. The shear wave propagation speed (SWS) was derived by calculating the

193 group velocity (infinite medium assumption neglecting dispersion). For this, we computed the

194 Radon transform of the velocity map, which represents the sum of all the pixel values over

195 straight lines in the image, oriented at different angles (Maksuti et al. 2016). We then selected

196 the maximum of the Radon transform, which corresponds to the angle of the most significant

197 wavefront of the map. This angle is directly related to the slope of the wavefront and therefore

198 to the SWS (Fig. 1d). The median value of SWS for the 5 position lines was retrieved and the

199 anterograde and retrograde SWS were averaged to obtain a single SWS value for the anterior

200 wall (a-SWS) and posterior wall (p-SWS). Moreover, a mean SWS value for each push was

201 calculated by averaging the different acquisitions and the inter-acquisitions variability was

202 assessed using the coefficient of variation (CV). Finally, a mean SWS value over the cardiac

203 cycle was calculated for each patient, for both walls, by averaging the 8 pushes.

\section{Pulse wave imaging post-processing}

205 The first two steps of pulse wave imaging post-processing are the same as for shear 206 wave elastography processing, i.e. arterial wall localization and frame-to-frame IQ cross207 correlation to retrieve the radial velocity map. With a $2000 \mathrm{~Hz}$ frame rate, the contrast of the 208 images was better than previously and enabled to use semi-automatic segmentation and 209 tracking algorithms. First, the sonographer manually segmented a longitudinal section where 210 the arterial walls appeared with a satisfactory quality (in plane and lumen/intima interface 211 visible) on the first frame. Then an automatic segmentation of the anterior and posterior wall 212 was performed and repeated every 50 frames (tradeoff between accuracy of wall localization 213 and computing time). The velocity values corresponding to the longitudinal elements of the 214 anterior and posterior wall were extracted and subtracted from each other to remove the 215 global motion of the artery. Thus, we obtained a space-time representation of the arterial wall 216 velocity (Fig. 2a). By averaging the velocity signal for all longitudinal positions and 217 integrating the mean velocity signal with respect to time we came up with an arterial wall 
distension signal exhibiting the expected shape of a pressure waveform with a clear systolic

219 upstroke delimiting the "foot of the wave" (FW), a systolic peak and a dicrotic notch (DN)

220 during late systole and before diastolic decay (Fig. 2b). Then, to identify the time-reference

221 points corresponding to the foot of the wave and the dicrotic notch, we used the classical

222 maximum of the second derivative method (Hermeling et al. 2009). Therefore, we calculated

223 the acceleration of the wall using a $2^{\text {nd }}$ order Kalman filter (Shumway and Stoffer 1982) (Fig.

224 2c). The arterial wall acceleration exhibited the expected two peaks corresponding to two

225 forward-propagating waves: the first wave corresponds to the beginning of systole (foot of the

226 wave), after aortic valve opening, while the second wave corresponds to the end of systole (or

227 dicrotic notch), after aortic valve closure. However, we observed that these peaks were

228 usually surrounded by other acceleration maxima or minima, which form visible wavefronts

229 in the space-time representation of arterial wall acceleration. Therefore, to ensure an accurate

230 comparison between subjects, we introduced a coding system of the different wavefronts (Fig.

$2312 \mathrm{~d})$ :

232 - At the foot of the wave: the latest maximum before systolic rise was numbered 0 , the following minimum was numbered 1 , the preceding minimum -1 and, when a preceding second maximum was visible, it as numbered -2 .

- At the dicrotic notch: the first maximum after the systolic peak was numbered 0 , the preceding and following minima were respectively numbered -1 and 1 and, when a of the acceleration maxima (or minima) was performed (Fig. 2e). The slope of the regression

240 lines gave the corresponding wave velocities and the correlation coefficient $\left(\mathrm{r}^{2}\right)$ was reported.

241 Then a quality analysis was performed by two independent reviewers which had not been 242 involved in data processing. Based on the graphs showing the regression lines and correlation 243 coefficients, they assigned a score between 0 (mediocre) and 4 (very good) to every wavefront. 
244 PWV estimates were accepted for further evaluation if the scores of both reviewers were

245 above 1. A mean PWV value per wavefront for each patient was calculated by averaging the 246 different acquisitions and the inter-acquisitions variability was assessed using the coefficient 247 of variation (CV). Finally, we calculated the difference between PWV measured at the foot of 248 the wave and at the dicrotic notch $(\Delta \mathrm{PWV})$, as well as the ratio $\Delta \mathrm{PWV} /$ carotid $\mathrm{PP}$ (Mirault et 249 al. 2015).

\section{Statistical analysis}

Data were compared between the two groups (NT and HT) using the non-parametric

252 Mann-Whitney test. Because of the small sample size, all data sets were assumed to be nonnormal. Correlations between parameters measured by the different techniques were analyzed by computing the Spearman-rank correlation coefficients. Multivariate models with robust regression (Huber's method) were also built to study the relationships between arterial stiffness, age and BP. The proportion of the variance of arterial stiffness explained by age and BP was evaluated through the partial coefficient of determination $\mathrm{R}^{2}$. Moreover, to study the variations of arterial stiffness with BP during the cardiac cycle, we ranked the 8 pushes in ascending order of the BP values corresponding to the push time (1 in diastole to 8 in systole).

260 We then used linear mixed models including the SWS, the age, the group (NT or HT), the BP and the rank of the push. We tested each variable as well as the interaction group*rank. Indeed, if significant, this interaction shows that the relationship between SWS and the level of BP (given by the rank) is different in NT and HT subjects. In addition, we compared SWS

264 between groups for a common level of $\mathrm{BP}, 100 \mathrm{mmHg}$, by performing a quadratic fitting of 265 the BP-SWS data of the 8 pushes per patient. Statistical analyses were completed using NCSS 26611 Statistical Software (2016) (NCSS, LLC. Kaysville, Utah, USA) and a p-value < 0.05 was 267 considered significant.

\section{Results}


The clinical characteristics of the population are presented in Table 1 and the arterial 271 parameters measured on the right carotid are reported in Table 2. The two groups were 272 comparable in terms of age, sex ratio, and heart rate. The HT group included more smokers and presented a higher BMI than the NT group. Brachial SBP, DBP and PP and carotid SBP and DBP were significantly higher in HT than in NT subjects. Note that $41 \%$ of HT patients were under antihypertensive treatment and that their mean SBP/DBP values, $143 / 81 \mathrm{mmHg}$ were relatively low in view of the threshold values defining hypertension $(140 / 90 \mathrm{mmHg})$. HT patients exhibited a significant increase in carotid diameter and wall cross-sectional area. Their IMT was also higher than for NT subjects, although not significant. These morphological changes are in accordance with previously observed remodeling of large arteries in hypertension (Laurent and Boutouyrie 2015). Moreover, we observed a significant 281 reduction of carotid distensibility and a significant increase in Young's elastic modulus and circumferential wall stress for HT patients (Table 2). Note that these changes in mechanical parameters are also consistent with previous studies (Bussy et al. 2000). In addition, aortic and carotid arterial stiffness evaluated by the reference techniques (applanation tonometry and echotracking) were found significantly higher in the HT group.

\section{Shear wave elastography, agreement with reference techniques and determinants}

Shear wave elastography acquisitions were available for only 25 of the subjects because appropriate device settings were under consideration for the first few patients. Feasibility and reproducibility data are detailed in Supplementary materials. The main clinical characteristics and arterial parameters of this sub-population are presented in Supplementary

291 Table 1. Note that the sub-population is slightly younger than the full study population (mean age 46 and 45 years for NTs and HTs vs. 49 and 50 years) but has very similar characteristics in terms of BP, carotid morphological and mechanical parameters. In addition, no significant

294 difference was observed between this group and the rest of the study population in terms of 295 clinical characteristics. We therefore considered this group as representative of the full study 
population. Mean values of SWS over the cardiac cycle (for the 8 pushes) are compared

297 between groups in Table 2. No difference was observed for p-SWS, whereas a-SWS was significantly higher for HTs than for NTs. Note that the average of the 8 pressure values corresponding to the 8 pushes was strongly correlated with carotid MBP $\left(r=0.99, p<10^{-6}\right)$ and brachial MBP $\left(r=0.92, p<10^{-6}\right)$, showing the adequacy of the sampling frequency with respect to the cardiac cycle duration.

We assessed the agreement between a-SWS, p-SWS and the reference techniques by using Spearman correlation tests considering the whole population (Table 3). The corresponding scatter plots are presented in Figure 3. We observed a significant positive correlation between aortic and carotid stiffness measured by the reference techniques $(\mathrm{r}=0.39$, $306 \mathrm{p}=0.003)$. a-SWS was strongly correlated with cfPWV $(\mathrm{r}=0.66, \mathrm{p}<0.001)$ and carPWV $307(\mathrm{r}=0.56, \mathrm{p}=0.003)$. However, we did not find any correlation between $\mathrm{p}-\mathrm{SWS}$ and cfPWV nor 308 carPWV.

309 Then we studied the relationship between SWS and the two main determinants of arterial 310 stiffness, age and BP, using a multivariate model (Table 4). Age and MBP were 311 independently associated with aortic and carotid stiffness, explaining together $44 \%$ and $36 \%$ 312 of their respective variance. Age and MBP appeared to be independent determinants of a-SWS, explaining respectively $14 \%$ and $21 \%$ of its variance. However, only age was

314 significantly associated with p-SWS with $18 \%$ of explained variance.

\section{Variations of shear wave speed with BP during the cardiac cycle}

316 To study the relationship between SWS and BP over the different pushes, we used 317 mixed models including the rank of the pushes in ascending order of corresponding BP, the 318 age and the group (NT or HT). a-SWS was significantly associated with BP level (rank of the 319 push $\left(\mathrm{p}<10^{-6}\right)$ but not $\mathrm{p}-\mathrm{SWS}(\mathrm{p}=0.19)$. Moreover, the association between a-SWS and the 320 group was close to significance level $(\mathrm{p}=0.052)$ but the interaction group*rank was not 321 significant $(\mathrm{p}=0.89)$. This shows that the relationship between a-SWS and BP does not differ 
between the NT and HT group. These observations are illustrated in Figure 4a where the mean SWS values are presented for the two groups. a-SWS increases with the push rank. Although mean a-SWS values seem higher for HTs than NTs, the evolution with pressure is similar for both groups. By contrast, for $\mathrm{p}-\mathrm{SWS}$, no clear tendency was observed nor any difference seen between groups. The analysis of the mixed model showed that there was a significant increase in a-SWS compared with rank 1 from rank 6 onwards $(\mathrm{p}=0.01)$ and even greater for rank $7(\mathrm{p}<0.001)$ and $8(\mathrm{p}<0.0001)$. However, the difference in $\mathrm{p}$-SWS compared with rank 1 was not significant until last rank (8) which was close to significance level $(\mathrm{p}=0.08)$.

Moreover, we analyzed with a mixed model the relationship between the actual (tonometry) BP values corresponding to each push, the push rank and the group (Fig. 4b). By construction, we observed a strong correlation of BP with the push rank $\left(\mathrm{p}<10^{-6}\right)$ and with the group $(\mathrm{p}<0.001)$. Nonetheless, the interaction push rank* group was not significant $(\mathrm{p}=0.5)$, showing that the relationship between BP and push rank was not different for NTs and HTs. Thus we could represent the relationship between SWS and BP for each group (Fig. 4c). We 337 observed again that a-SWS increases with BP. The curve of the HT group is shifted towards 338 higher BP values but not higher a-SWS values. Indeed, the curves of both groups are 339 overlapping in the range of common BP values. Regarding p-SWS, as noted previously, no 340 association was observed with BP nor difference between groups.

341 To further test our hypothesis regarding the absence of difference in intrinsic wall 342 stiffness between HTs and NTs, we fitted the BP-(a-SWS) relationship with a second order 343 polynomial function for each subject individually. We then interpolated the a-SWS value 344 calculated by the model for a pressure of $100 \mathrm{mmHg}$ and compared it between the two groups 345 (Table 2). We did not find any difference between NTs and HTs $(\mathrm{p}=0.23)$ for a-SWS at a 346 common pressure of $100 \mathrm{mmHg}$. Furthermore, we observed that in multivariate analysis 
a-SWS at $100 \mathrm{mmHg}$ was significantly correlated with age $(\mathrm{p}=0.002)$ independently of the 348 mean BP of the patient.

\section{Ultrafast imaging of the pulse wave}

PWV values measured by ultrafast echography in diastole at the foot of the wave (ufPWV-FW) and in end systole at the dicrotic notch (ufPWV-DN) are compared between the two groups in Table 2 (see Supplementary materials for feasibility and reproducibility data).

353 No significant differences were found between the two groups for any parameter measured by ultrafast imaging of the pulse wave. However, carPWV and cfPWV were significantly higher in the HT group even when considering only the subjects having had ultrafast imaging or shear wave elastography (data not shown).

We evaluated the agreement between PWV measured by ultrafast imaging and the reference techniques by using Spearman correlation tests considering the whole population (Table 3). The corresponding scatter plots are presented in Figure 3. ufPWV-DN appeared significantly correlated with carotid stiffness measured by echotracking $(r=0.49, \mathrm{p}=0.001)$ but not with aortic stiffness. Note that no correlation was observed with ufPWV-FW.

362 We then studied the relationship between arterial stiffness and its two main determinants, age 363 and BP, using a multivariate model (Table 4). We observed that ufPWV-FW and ufPWV-DN were not associated with age nor with MBP. Finally, we did not find any association with age of the difference between PWV measured by ultrafast imaging at the foot of the wave and at 366 the dicrotic notch $(\mathrm{r}=0.10, \mathrm{p}=0.59)$ as well as this difference normalized by carotid $\mathrm{PP}(\mathrm{r}=0.11$, $367 \mathrm{p}=0.56$ ), even when adjusted for BP. Note that when considering the NT subjects only, 368 ufPWV-DN was associated with age, independently of MBP, with $39 \%$ of explained variance 369 (see Supplementery Table 3).

\section{Discussion}

We have implemented two methods based on ultrafast echography to measure carotid 372 arterial stiffness of hypertensive patients and normotensive subjects: first by measuring the 
speed of propagation of artificial shear waves generated along the cardiac cycle in the anterior

374 and posterior carotid wall, second through carotid PWV by ultrafast imaging of the pulse wave propagation. The main results were that shear wave speed on the anterior wall is strongly associated with reference techniques, as well as with age and BP independently. Moreover, with anterior wall shear wave analysis, we demonstrate that normotensives and

378 hypertensives exhibit similar mechanical behavior of carotid wall, when studied at the same 379 pressure. By contrast, shear wave speed on the posterior wall showed a significant association with age independently of BP but no association with BP nor with reference techniques. PWV

381 at the dicrotic notch was associated with carotid stiffness only and PWV at the foot of the 382 wave showed no association at all.

\section{Agreement with reference techniques}

We have shown that a-SWS is correlated with carotid and aortic PWV while carotid PWV measured by ultrafast imaging of the pulse wave at end systole (at the dicrotic notch) is correlated with carotid PWV measured by echotracking only. In contrast, we did not find any association with the reference techniques of carotid p-SWS nor ufPWV-FW. Regarding carotid ufPWV-FW, previous publications have shown that local PWV measurement at the "foot of the wave" could be disturbed by early wave reflections and associated with a lower reproducibility than measurement at the dicrotic notch (20\% variation coefficient instead of 10\%) (Hermeling et al. 2008; Hermeling et al. 2009). In the studies by Hermeling, PWV was calculated by linear regression after identifying the foot of the wave (or the dicrotic notch) for 14 ultrasound lines every $1.26 \mathrm{~mm}$ with a frame rate around $600 \mathrm{~Hz}$. The low distance combined with the frame rate might partly explain these results. In any case, we observed comparable results in the present study by increasing both the distance $(40 \mathrm{~mm})$ and the frame rate $(2 \mathrm{kHz})$. Therefore, the obtained results confirm the important variability of local PWV measurement at the foot of the wave and the better quality of data obtained at the dicrotic notch. The explanation provided by Hermeling $(2008 ; 2009)$ was the presence of early wave 
reflections which make the analysis of the foot of the wave complex. Indeed, the wavefronts

400 observed at the foot of the wave are very complex and sometimes difficult to identify,

401 although we paid particular attention in their identification. Contrary to late reflections which 402 can be observed as wave travelling in opposite directions, early reflected waves are 403 superimposed with forward waves and cannot be individualized.

404 Concerning p-SWS, we also found the highest inter-acquisitions variability (20.5\%).

405 This low reproducibility can be attributed to the lower quality of the distance-time maps of 406 wall velocity obtained for the posterior wall compared to the anterior wall. Due to the 407 posterior wall being deeper in the tissue, the quality of the ultrasound signal could be altered. 408 Another hypothesis is the difference in anatomical location between the anterior and posterior 409 carotid walls. Indeed, the anterior wall is located below the jugular vein. It is attached to the 410 vein wall but is well separated from the other surrounding tissues and can move quite freely. 411 On the other hand, the posterior wall is directly attached to the underneath muscular tissues. 412 This binding could affect the wall movement and stiffness. This influence could be rather 413 limited for the anterior wall but more significant for the posterior wall, explaining the lack of 414 agreement between the local posterior wall stiffness and the reference techniques that take 415 into account the whole vessel distension.

Association with age

As expected, we found independent associations with age and MBP of aortic and carotid stiffness measured by the reference techniques. Even in this small number of subjects these associations were meaningful and comparable to previous larger studies (Engelen et al. 2015; Paini et al. 2006; The Reference Values for Arterial Stiffness' Collaboration 2010). We have shown that a-SWS (and to a lesser extent p-SWS) was associated with age independently of MBP. Yet SWS is a parameter representing the intrinsic stiffness of the arterial wall material, which can be compared to the Young's incremental elastic modulus measured in 424 previous studies. In the present analysis, we have privileged SWS because it is directly 
measured, and any manipulation can increase the variability of the parameter by transmission

426 of measurement errors in formulas. It has been shown that ageing was associated with an 427 increase in the Young's incremental elastic modulus (Bussy et al. 2000). Therefore, the 428 present results confirm this relationship with a direct measurement instead of a calculation 429 based on BP.

We showed that ufPWV-DN, ufPWV-FW and their difference were not associated with age. This is at contrast with a recent study which has shown that these parameters were associated with age independently of BP in a population of 102 healthy normotensive subjects (Mirault et al. 2015). For proper comparison, we analyzed the association with age and MBP in the NT group only (Supplementary Table 3). We found that ufPWV-DN was significantly associated with age with $39 \%$ of explained variance $(\mathrm{p}=0.002)$, which is in accordance with Mirault's results. However, ufPWV-FW, $\triangle \mathrm{PWV}$ and $\triangle \mathrm{PWV} / \mathrm{PP}$ still showed no association with age. We acknowledge that our sample size is low and should be increased in order to ensure a meaningful comparison. In its current form and in our hands, pulse wave imaging seems to lack robustness. Our results highlight the importance of developing more robust 440 analysis tools for the precise quantification of the PWV.

\section{Association with BP}

We found that mean a-SWS was significantly higher for the HT group than the NT 443 group and was significantly correlated with MBP, independently of age. Consequently, a-SWS appears to be a very interesting parameter for hypertension management and detection,

445 especially since its measurement does not require BP measurements. Studies on larger and 446 more varied populations should be carried out in order to better understand this new variable. 447 Moreover, we have shown that this index of local intrinsic stiffness of the anterior wall 448 changes during the cardiac cycle and significantly increases with BP. This confirms, in a 449 larger population, the preliminary results obtained by Couade et al. (2010). Furthermore, the 450 fact that the rank*group interaction was not significant demonstrates that the correlation 
between a-SWS and BP was not different between the HT and NT group. Therefore, the

452 observed difference in a-SWS between the two groups is essentially explained by the 453 difference in BP. In addition, the (a-SWS)-BP curves of the two groups overlap in the 454 common pressure range and exhibit no upward shift. These results show that the intrinsic 455 stiffness of the arterial wall is not increased in HT patients compared to NT subjects of same 456 age and sex when it is measured at the same BP level. The apparent increase in arterial 457 stiffness of HTs compared to NTs is mainly explained by their higher BP. Hence, our results 458 confirm by a direct method, independent of $\mathrm{BP}$, that the absence of increase in intrinsic 459 arterial stiffness of the arterial wall of HTs (Bussy et al. 2000) is not a tautology caused by BP 460 values in formulas. However, because of the small size of our groups, we were not able to 461 perform analyses according to age groups neither to study the evolution of intrinsic arterial 462 stiffness of young HTs. The absence of increase in arterial stiffness in HTs might be 463 explained by the antihypertensive treatment allowing a partial control of hypertension and an at least partial correction of the underlying mechanical abnormality. However, because of the small sample size we could not test this hypothesis in the present study.

A novel finding from this study is the fact that we observed different results for the 467 anterior and posterior wall. Indeed, p-SWS appeared correlated with age but not with BP and 468 was not different between the HT and NT group. We recall that the quality of the posterior 469 wall data was lower than for the anterior wall and the inter-acquisitions variability of p-SWS 470 was much higher than for a-SWS (20.5\% compared to $8.3 \%$ ). This might be due to the 471 alteration of the ultrasound shear waves and signals with depth. Yet an asymmetric motion of 472 the arterial anterior and posterior walls could explain the observed difference and has 473 previously been observed in rats using high-resolution ultrasound (Nam et al. 2014). Indeed, 474 circumferential stress and strain related to pressure and diameter pulsatility have generally 475 been considered to be equally distributed over the entire circumference of the artery. However, 476 the fact that the stiffness of the posterior wall does not increase with BP could be explained by 
a lower stretch on this side compared to the anterior side, which deforms more. In addition, as

478 we previously mentioned, the difference in anatomical location between the anterior wall, in 479 close proximity to the vein, and the posterior wall, in close proximity to the underneath 480 muscular tissues might also account for this discrepancy. Transverse analyses in the 481 circumferential direction would help to further investigate this aspect.

Finally, we have shown that ufPWV-FW and ufPWV-DN were not significantly 483 different between the HT and the NT group. Note that $41 \%$ of HT patients were under antihypertensive treatments, which could affect carotid and aortic stiffness adaptation to the actual level of BP. Yet, groups were too small to test the effect of treatments. Nevertheless, carPWV and cfPWV were found to be significantly higher for the HT group than for the NT group. Moreover, the multivariate analysis showed that the reference indices of aortic and carotid stiffness were significantly correlated with MBP independently of age, whereas ufPWV-FW and ufPWV-DN were not associated with MBP. Therefore, PWV measured by ultrafast ultrasound still needs improvement before being proposed for measuring the evolution of arterial stiffness in the presence of hypertension.

\section{Limitations and perspectives}

As previously mentioned, the sample size of our population was smaller than foreseen because of technical problems at the beginning of the study. Besides, an important part of included HT patients were under antihypertensive treatment and the pressure values of the HT group are therefore close to the thresholds defining hypertension. Hence, there was no marked contrast between the two groups considered in the present study, which helped for comparison

498 because of the BP overlap, but could underestimate the effect of high, untreated hypertension. Actual pulse wave propagation wavefronts were complex to decipher. It appeared that some wavefronts were very clear whereas $\mathbf{R}^{2}$ was low. To limit subjectivity, we used a scoring system rather than a selection based on $\mathbf{R}^{2}$. This procedure was only used for 

applications.

We measured the group velocity of shear waves by neglecting dispersion phenomena.

506 Yet several studies on arterial phantoms have shown that using the group velocity led to an 507 underestimation of the shear and Young's moduli compared to using the phase velocity 508 (Maksuti et al. 2016; Widman et al. 2016). However, one study on an ex vivo porcine carotid 509 artery has shown that the calculation of Young's modulus based on the group velocity and the 510 Moens-Korteweg equation gave very similar results compared to the approach using the phase 511 velocity (Bernal et al. 2011). The calculation of phase velocity requires a more complex 512 processing of acquired data. Although the present study suggests that the group velocity 513 approach is sufficient to retrieve relevant parameters in vivo, it would be interesting to 514 evaluate the shear waves phase velocity in our population. Besides, we have evaluated the 515 SWS in the longitudinal direction of the artery only. Yet the arterial mechanical behavior is 516 anisotropic and one ex vivo study on a horse aorta has shown that the variations of SWS with 517 deformation were more important in the circumferential direction than in the longitudinal one 518 (Shcherbakova et al. 2014). Hence, it would be interesting to include measurements in the 519 circumferential direction in future studies.

The results of the application of shear wave elastography for the measurement of arterial stiffness in vivo seem very encouraging and further studies should be carried out to

522 better understand the retrieved indices of stiffness. Acquisitions are simple, however, in its 523 present form, post-processing is very complex because we need to integrate data from 524 tonometry and echotracking. Improvement in hardware and signal processing (ECG-gated 525 sequence of diameter measurement similar to the echotracking) could be integrated into the 526 ultrafast ultrasound scanner.

\section{Conclusion}


528 The approach proposed in this study allowed for the assessment of carotid arterial stiffness in

529 hypertensive patients and healthy subjects via a new technique using ultrafast ultrasound, that 530 does not depend on BP. Anterior wall SWS appears as the best candidate to evaluate local

531 arterial stiffness because of its good correlation with age, BP and reference methods (aortic 532 stiffness and carotid distensibility). In addition, we have demonstrated with a method not 533 requiring BP that the intrinsic arterial stiffness of HT patients is not increased compared to 534 healthy subjects of the same age when measured at a common BP level. Finally, we have 535 confirmed that SWE is able to capture the increase in arterial stiffness with BP during the 536 cardiac cycle.

\section{Acknowledgements}

538 Clinical Investigation Center provided logistic support. The French Society of Cardiology 539 sponsored the study. We thank Rachel Climie for proofreading the article.

\section{$540 \quad$ Funding sources}

541 Self-financed on recurrent grant from INSERM. 


\section{References}

Ben-Shlomo Y, Spears M, Boustred C, May M, Anderson SG, Benjamin EJ, Boutouyrie P, Cameron J, Chen C-H, Cruickshank JK, Hwang S-J, Lakatta EG, Laurent S, Maldonado J, Mitchell GF, Najjar SS, Newman AB, Ohishi M, Pannier B, Pereira T, Vasan RS, Shokawa T, Sutton-Tyrell K, Verbeke F, Wang K-L, Webb DJ, Willum Hansen T, Zoungas S, McEniery CM, Cockcroft JR, Wilkinson IB. Aortic Pulse Wave Velocity Improves Cardiovascular Event Prediction: An Individual Participant MetaAnalysis of Prospective Observational Data From 17,635 Subjects. J Am Coll Cardiol 2014;63:636-646.

Bercoff J, Tanter M, Fink M. Supersonic shear imaging: a new technique for soft tissue elasticity mapping. IEEE Trans Ultrason Ferroelectr Freq Control 2004;51:396-409.

Bernal M, Nenadic I, Urban MW, Greenleaf JF. Material property estimation for tubes and arteries using ultrasound radiation force and analysis of propagating modes. $\mathrm{J}$ Acoust Soc Am 2011;129:1344-1354.

Boutouyrie P, Bussy C, Lacolley P, Girerd X, Laloux B, Laurent S. Association Between Local Pulse Pressure, Mean Blood Pressure, and Large-Artery Remodeling. Circulation 1999;100:1387-1393.

Bussy C, Boutouyrie P, Lacolley P, Challande P, Laurent S. Intrinsic Stiffness of the Carotid Arterial Wall Material in Essential Hypertensives. Hypertension 2000;35:1049-1054.

Couade M, Pernot M, Messas E, Emmerich J, Hagège A, Fink M, Tanter M. Ultrafast imaging of the arterial pulse wave. IRBM 2011;32:106-108. 
Couade M, Pernot M, Prada C, Messas E, Emmerich J, Bruneval P, Criton A, Fink M, Tanter M. Quantitative Assessment of Arterial Wall Biomechanical Properties Using Shear Wave Imaging. Ultrasound Med Biol 2010;36:1662-1676.

Engelen L, Bossuyt J, Ferreira I, van Bortel LM, Reesink KD, Segers P, Stehouwer CD, Laurent S, Boutouyrie P. Reference values for local arterial stiffness. Part A: carotid artery. J Hypertens 2015;33:1981-1996.

Fung YC. Biomechanics: Mechanical Properties of Living Tissues. Springer Science \& Business Media, 1993.

Hermeling E, Reesink KD, Kornmann LM, Reneman RS, Hoeks AP. The dicrotic notch as alternative time-reference point to measure local pulse wave velocity in the carotid artery by means of ultrasonography. J Hypertens 2009;27:2028-2035.

Hermeling E, Reesink KD, Reneman RS, Hoeks APG. Confluence of incident and reflected waves interferes with systolic foot detection of the carotid artery distension waveform. J Hypertens 2008;26:2374-2380.

Laurent S, Boutouyrie P. The Structural Factor of Hypertension. Circ Res 2015;116:10071021.

Laurent S, Caviezel B, Beck L, Girerd X, Billaud E, Boutouyrie P, Hoeks A, Safar M. Carotid artery distensibility and distending pressure in hypertensive humans. Hypertension 1994;23:878-883.

Laurent S, Cockcroft J, Bortel LV, Boutouyrie P, Giannattasio C, Hayoz D, Pannier B, Vlachopoulos C, Wilkinson I, Struijker-Boudier H. Expert consensus document on arterial stiffness: methodological issues and clinical applications. Eur Heart J 2006;27:2588-2605. 
Laurent S, Marais L, Boutouyrie P. The Noninvasive Assessment of Vascular Aging. Can J Cardiol 2016;32:669-679.

Maksuti E, Widman E, Larsson D, Urban MW, Larsson M, Bjällmark A. Arterial Stiffness Estimation by Shear Wave Elastography: Validation in Phantoms with Mechanical Testing. Ultrasound Med Biol 2016;42:308-321.

Mancia G, Fagard R, Narkiewicz K, Redon J, Zanchetti A, Böhm M, Christiaens T, Cifkova R, De Backer G, Dominiczak A, Galderisi M, Grobbee DE, Jaarsma T, Kirchhof P, Kjeldsen SE, Laurent S, Manolis AJ, Nilsson PM, Ruilope LM, Schmieder RE, Sirnes PA, Sleight P, Viigimaa M, Waeber B, Zannad F, Redon J, Dominiczak A, Narkiewicz K, Nilsson PM, Burnier M, Viigimaa M, Ambrosioni E, Caufield M, Coca A, Olsen MH, Schmieder RE, Tsioufis C, van de Borne P, Zamorano JL, Achenbach S, Baumgartner H, Bax JJ, Bueno H, Dean V, Deaton C, Erol C, Fagard R, Ferrari R, Hasdai D, Hoes AW, Kirchhof P, Knuuti J, Kolh P, Lancellotti P, Linhart A, Nihoyannopoulos P, Piepoli MF, Ponikowski P, Sirnes PA, Tamargo JL, Tendera M, Torbicki A, Wijns W, Windecker S, Clement DL, Coca A, Gillebert TC, Tendera M, Rosei EA, Ambrosioni E, Anker SD, Bauersachs J, Hitij JB, Caulfield M, De Buyzere M, De Geest S, Derumeaux GA, Erdine S, Farsang C, Funck-Brentano C, Gerc V, Germano G, Gielen S, Haller H, Hoes AW, Jordan J, Kahan T, Komajda M, Lovic D, Mahrholdt H, Olsen MH, Ostergren J, Parati G, Perk J, Polonia J, Popescu BA, Reiner Ž, Rydén L, Sirenko Y, Stanton A, Struijker-Boudier H, Tsioufis C, van de Borne P, Vlachopoulos C, Volpe M, Wood DA. 2013 ESH/ESC Guidelines for the management of arterial hypertensionThe Task Force for the management of arterial hypertension of the European Society of Hypertension (ESH) and of the European Society of Cardiology (ESC). Eur Heart J 2013;34:2159-2219. 
611 Messas E, Pernot M, Couade M. Arterial wall elasticity: State of the art and future prospects. Diagn Interv Imaging 2013;94:561-569.

613

Millasseau SC, Stewart AD, Patel SJ, Redwood SR, Chowienczyk PJ. Evaluation of CarotidFemoral Pulse Wave Velocity. Hypertension 2005;45:222-226.

Mirault T, Pernot M, Frank M, Couade M, Niarra R, Azizi M, Emmerich J, Jeunemaître X, Fink M, Tanter M, Messas E. Carotid stiffness change over the cardiac cycle by ultrafast ultrasound imaging in healthy volunteers and vascular Ehlers-Danlos syndrome: J Hypertens 2015;33:1890-1896.

Montaldo G, Tanter M, Bercoff J, Benech N, Fink M. Coherent plane-wave compounding for very high frame rate ultrasonography and transient elastography. IEEE Trans Ultrason Ferroelectr Freq Control 2009;56:489-506.

Nam K-H, Bok T-H, Jin C, Paeng D-G. Asymmetric radial expansion and contraction of rat carotid artery observed using a high-resolution ultrasound imaging system. Ultrasonics 2014;54:233-240.

Nichols W, O’Rourke M, Vlachopoulos C. McDonald's Blood Flow in Arteries, Sixth Edition: Theoretical, Experimental and Clinical Principles. CRC Press, 2011.

Paini A, Boutouyrie P, Calvet D, Tropeano A-I, Laloux B, Laurent S. Carotid and Aortic Stiffness: determinants of discrepancies. Hypertension 2006;47:371-376.

Paini A, Boutouyrie P, Calvet D, Zidi M, Agabiti-Rosei E, Laurent S. Multiaxial Mechanical Characteristics of Carotid Plaque Analysis by Multiarray Echotracking System. Stroke 2007;38:117-123. 
632 Pernot M, Fujikura K, Fung-Kee-Fung SD, Konofagou EE. ECG-gated, Mechanical and

633

634

635

636

637

638

639

640

641

642

643

644

645

646

647

648

649 Electromechanical Wave Imaging of Cardiovascular Tissues In Vivo. Ultrasound Med Biol 2007;33:1075-1085.

Royer D, Dieulesaint E. Elastic Waves in Solids I: Free and Guided Propagation. Berlin Heidelberg: Springer-Verlag, 2000 [cited 2018 Mar 1]. Available from: //www.springer.com/la/book/9783540659327

Shcherbakova DA, Papadacci C, Swillens A, Caenen A, Bock SD, Saey V, Chiers K, Tanter M, Greenwald SE, Pernot M, Segers P. Supersonic Shear Wave Imaging to Assess Arterial Nonlinear Behavior and Anisotropy: Proof of Principle via Ex Vivo Testing of the Horse Aorta. Adv Mech Eng 2014;6:272586.

Shumway RH, Stoffer DS. An Approach to Time Series Smoothing and Forecasting Using the Em Algorithm. J Time Ser Anal 1982;3:253-264.

Tanter M, Bercoff J, Sandrin L, Fink M. Ultrafast compound imaging for 2-D motion vector estimation: application to transient elastography. IEEE Trans Ultrason Ferroelectr Freq Control 2002;49:1363-1374.

The Reference Values for Arterial Stiffness' Collaboration. Determinants of pulse wave velocity in healthy people and in the presence of cardiovascular risk factors: “establishing normal and reference values.” Eur Heart J 2010;31:2338-2350.

Van Bortel LM, Laurent S, Boutouyrie P, Chowienczyk P, Cruickshank JK, De Backer T, Filipovsky J, Huybrechts S, Mattace-Raso FUS, Protogerou AD, Schillaci G, Segers P, Vermeersch S, Weber T. Expert consensus document on the measurement of aortic stiffness in daily practice using carotid-femoral pulse wave velocity: J Hypertens 2012;30:445-448. 
655 van Sloten TT, Schram MT, van den Hurk K, Dekker JM, Nijpels G, Henry RMA, Stehouwer 656 CDA. Local Stiffness of the Carotid and Femoral Artery Is Associated With Incident 657 Cardiovascular Events and All-Cause Mortality: The Hoorn Study. J Am Coll Cardiol $658 \quad 2014 ; 63: 1739-1747$.

659 Vlachopoulos C, Aznaouridis K, Stefanadis C. Prediction of Cardiovascular Events and All660 Cause Mortality With Arterial Stiffness: A Systematic Review and Meta-Analysis. J $661 \quad$ Am Coll Cardiol 2010;55:1318-1327.

662 Widman E, Maksuti E, Amador C, Urban MW, Caidahl K, Larsson M. Shear Wave 663 Elastography Quantifies Stiffness in Ex Vivo Porcine Artery with Stiffened Arterial 664 Region. Ultrasound Med Biol 2016;42:2423-2435.

665

666 


\section{Figure captions list}

668

669 Fig. 1. The main steps of the shear wave elastography post-processing used to derive the shear 670 wave speed (SWS). (a) Manual delimitation of anterior and posterior wall on the first 671 ultrasound image: red crosses correspond to the manually positioned points (3 for each wall) 672 and blue dotted lines to the entire wall position after second order polynomial interpolation 673 between corresponding points. (b) Temporally aligned mean cycles of CCA diameter 674 measured by echotracking and CCA BP measured by applanation tonometry. The time points 675 corresponding to the 8 pushes were identified knowing the time delay between the R-wave 676 peak of the ECG and the foot of the pressure wave. (c) IQ images of two pushes used to 677 assess the change in position of the CCA walls delimited by 5 position lines. (d) 678 Spatiotemporal maps of wall velocity corresponding to the 5 position lines of anterior and 679 posterior wall. The shear wave speed (SWS) was derived by calculating the slope of the main 680 retrograde and anterograde wavefronts using the maximum of the Radon transform.

682 Fig. 2. The main steps of the pulse wave imaging post-processing used to derive the pulse 683 wave velocity (PWV) at the foot of the wave (FW) and at the dicrotic notch (DN). (a) 684 Spatiotemporal map of wall velocity (anterior and posterior walls were subtracted from each 685 other). (b) Arterial wall distension curve obtained by integrating the mean velocity signal over 686 the longitudinal distance. (c) Spatiotemporal map of wall acceleration used to identify the 687 wavefronts corresponding to FW and DN. (d) Acceleration trace of the middle of the wall 688 exhibiting characteristic wavefronts and their coding. (e) Corresponding PWV values are 689 given by the slope of the wavefronts calculated by robust linear regression. 
691 Fig. 3. Scatter plots evaluating the agreement between PWV measured by shear wave 692 elastography, ultrafast imaging and the reference techniques: (a) carotid PWV measured by 693 echotracking and (b) carotid-femoral PWV measured by applanation tonometry.

694

695 Fig. 4. (a) Relationship between SWS and pressure level represented by push rank for anterior 696 and posterior wall. Data presented are mean values for the NT $(n=14)$ and the HT group 697 ( $\mathrm{n}=11$ ). (b) Mean carotid pressure values corresponding to each push rank for the two groups. 698 (c) Relationship between SWS and carotid pressure over the cardiac cycle for the two groups. 699 Error bars represent standard errors of the mean. 
Table 1. Clinical characteristics of the population

\begin{tabular}{lccc}
\hline Parameters & $\begin{array}{c}\text { NT Subjects } \\
(\mathrm{n}=27)\end{array}$ & $\begin{array}{c}\text { HT Patients } \\
(\mathrm{n}=29)\end{array}$ & $\mathrm{p}$ \\
\hline Age (y) & $49 \pm 12$ & $50 \pm 12$ & 0.92 \\
Gender ratio (male/female) & $15 / 12$ & $14 / 15$ & 0.78 \\
Smoking (yes/no) & $1 / 26$ & $16 / 13$ & $<\mathbf{0 . 0 0 1}$ \\
Treatment for hypertension (yes/no) & $0 / 27$ & $12 / 17$ & $<\mathbf{0 . 0 0 1}$ \\
BMI (kg/m $\left.{ }^{2}\right)$ & $24.2 \pm 3.3$ & $27.1 \pm 4.2$ & $\mathbf{0 . 0 0 7}$ \\
Heart rate (bpm) & $62 \pm 8$ & $66 \pm 8$ & 0.09 \\
Brachial BP & $119 \pm 14$ & $143 \pm 13$ & $<\mathbf{0 . 0 0 1}$ \\
$\quad$ SBP (mmHg) & $66 \pm 7$ & $82 \pm 9$ & $<\mathbf{0 . 0 0 1}$ \\
$\quad$ DBP (mmHg) & $53 \pm 9$ & $61 \pm 7$ & $\mathbf{0 . 0 0 1}$ \\
$\quad$ PP (mmHg) & $113 \pm 20$ & $140 \pm 23$ & $<\mathbf{0 . 0 0 1}$ \\
Carotid BP & $65 \pm 9$ & $81 \pm 9$ & $<\mathbf{0 . 0 0 1}$ \\
SBP (mmHg) & $49 \pm 20$ & $59 \pm 20$ & 0.06 \\
$\quad$ DBP (mmHg) & & & \\
PP (mmHg) & & &
\end{tabular}

BMI: body mass index. Mean \pm SD

701 
Table 2. Arterial parameters of the right CCA in NT Subjects and HT Patients

\begin{tabular}{|c|c|c|c|}
\hline Parameters & $\begin{array}{l}\text { NT Subjects } \\
\quad(\mathrm{n}=27)\end{array}$ & $\begin{array}{l}\text { HT Patients } \\
\quad(n=29)\end{array}$ & $\mathrm{p}$ \\
\hline External Diameter (mm) & $6.92 \pm 0.57$ & $7.59 \pm 0.84$ & 0.002 \\
\hline Distension $(\mu \mathrm{m})$ & $443 \pm 161$ & $419 \pm 129$ & 0.61 \\
\hline $\mathrm{IMT}(\mu \mathrm{m})$ & $549 \pm 118$ & $595 \pm 112$ & 0.08 \\
\hline WCSA $\left(\mathrm{mm}^{2}\right)$ & $11.0 \pm 2.7$ & $13.2 \pm 3.4$ & 0.008 \\
\hline Wall to lumen ratio & $0.19 \pm 0.05$ & $0.19 \pm 0.04$ & 0.95 \\
\hline$\sigma_{\text {circ }}(\mathrm{kPa})$ & $62.2 \pm 14.6$ & $76.9 \pm 15.6$ & 0.001 \\
\hline Distensibility $\left(\mathrm{MPa}^{-1}\right)$ & $28.0 \pm 14.4$ & $19.7 \pm 10.8$ & 0.015 \\
\hline Einc $(\mathrm{kPa})$ & $472 \pm 227$ & $667 \pm 341$ & 0.01 \\
\hline $\operatorname{carPWV}(\mathrm{m} / \mathrm{s})$ & $6.6 \pm 1.7$ & $7.8 \pm 2.1$ & 0.015 \\
\hline $\operatorname{cfPWV}(\mathrm{m} / \mathrm{s})$ & $7.7 \pm 1.6$ & $9.0 \pm 1.3$ & 0.001 \\
\hline Mean a-SWS $(\mathrm{m} / \mathrm{s}){ }^{*}$ & $5.2 \pm 1.0$ & $5.9 \pm 0.9$ & 0.03 \\
\hline Mean p-SWS $(\mathrm{m} / \mathrm{s})^{*}$ & $7.4 \pm 2.4$ & $6.8 \pm 1.4$ & 0.70 \\
\hline a-SWS at $100 \mathrm{mmHg}(\mathrm{m} / \mathrm{s})^{*}$ & $5.4 \pm 1.0$ & $5.9 \pm 1.1$ & 0.23 \\
\hline ufPWV-FW $0(\mathrm{~m} / \mathrm{s})^{*}$ & $6.4 \pm 1.7$ & $6.2 \pm 1.8$ & 0.97 \\
\hline ufPWV-DN $0(\mathrm{~m} / \mathrm{s})^{*}$ & $7.3 \pm 1.4$ & $8.3 \pm 3.3$ & 0.38 \\
\hline$\Delta \mathrm{PWV}(\mathrm{m} / \mathrm{s})^{*}$ & $0.8 \pm 2.1$ & $1.4 \pm 2.5$ & 0.57 \\
\hline$\Delta \mathrm{PWV} /$ carotid $\mathrm{PP}(\mathrm{m} / \mathrm{s} / \mathrm{mmHg})^{*}$ & $0.012 \pm 0.052$ & $0.023 \pm 0.041$ & 0.57 \\
\hline
\end{tabular}

Mean $\pm \mathrm{SD}$; $*$ means that the number of subjects is smaller for these parameters.

SWS was obtained in 14 and 11 normotensives and hypertensives respectively, ufPWV-FW was obtained in 21 and 14 normotensives and hypertensives respectively, ufPWV-DN in 24 and 20 normotensives and hypertensives respectively. 
Table 3. Spearman correlation matrix between arterial stiffness measured by the different techniques.

\begin{tabular}{lcccc}
\hline Parameters & \multicolumn{2}{c}{ carPWV } & \multicolumn{2}{c}{ cfPWV } \\
\cline { 2 - 5 } cfPWV & $\mathrm{r}$ & $\mathrm{p}$ & $\mathrm{r}$ & $\mathrm{p}$ \\
\cline { 2 - 5 } Mean a-SWS & 0.39 & $\mathbf{0 . 0 0 3}$ & & \\
Mean p-SWS & 0.56 & $\mathbf{0 . 0 0 3}$ & 0.66 & $<\mathbf{0 . 0 0 1}$ \\
ufPWV-FW & 0.30 & $\mathrm{NS}$ & 0.20 & $\mathrm{NS}$ \\
ufPWV-DN & 0.05 & $\mathrm{NS}$ & 0.02 & $\mathrm{NS}$ \\
\hline
\end{tabular}

705 
Table 4. Multivariate analysis of the association with age and brachial mean blood pressure of aortic and carotid stiffness measured by the different methods.

\begin{tabular}{|c|c|c|c|c|c|}
\hline cfPWV & $(n=56)$ & $R$ coef & $95 \% \mathrm{CL}$ & $\mathbf{R}^{2}$ & $\mathbf{p}$ \\
\hline age (10 years) & & 0.451 & {$[0.193 ; 0.708]$} & 0.120 & 0.001 \\
\hline MBP (10 mmHg) & & 0.574 & {$[0.373 ; 0.774]$} & 0.321 & $<0.001$ \\
\hline carPWV & $(n=56)$ & & & & \\
\hline age (10 years) & & 0.544 & {$[0.247 ; 0.840]$} & 0.149 & 0.001 \\
\hline MBP (10 mmHg) & & 0.530 & {$[0.289 ; 0.771]$} & 0.213 & $<0.001$ \\
\hline a-SWS & $(n=25)$ & & & & \\
\hline age (10 years) & & 0.304 & {$[0.022 ; 0.586]$} & 0.136 & 0.036 \\
\hline MBP (10 mmHg) & & 0.257 & {$[0.067 ; 0.447]$} & 0.214 & 0.010 \\
\hline p-SWS & $(n=25)$ & & & & \\
\hline age (10 years) & & 0.683 & {$[0.053 ; 1.313]$} & 0.184 & 0.035 \\
\hline MBP (10 mmHg) & & 0.056 & {$[-0.403 ; 0.515]$} & 0.002 & 0.802 \\
\hline ufPWV-FW & $(n=35)$ & & & & \\
\hline age (10 years) & & 0.222 & {$[-0.251 ; 0.695]$} & 0.028 & 0.347 \\
\hline MBP (10 mmHg) & & -0.034 & {$[-0.404 ; 0.336]$} & 0.001 & 0.853 \\
\hline ufPWV-DN & $(n=44)$ & & & & \\
\hline age (10 years) & & 0.271 & {$[-0.170 ; 0.711]$} & 0.034 & 0.222 \\
\hline MBP (10 mmHg) & & 0.269 & {$[-0.080 ; 0.618]$} & 0.054 & 0.127 \\
\hline
\end{tabular}


a. Standard ultrasound image and manual wall delimitation

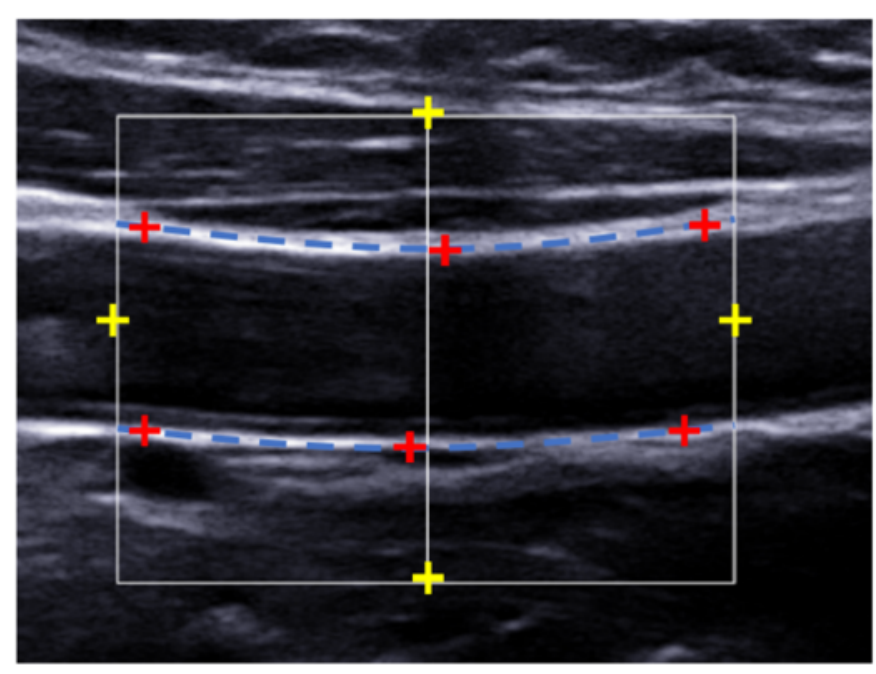

b. Diameter and pressure cycles with 8 pushes identified

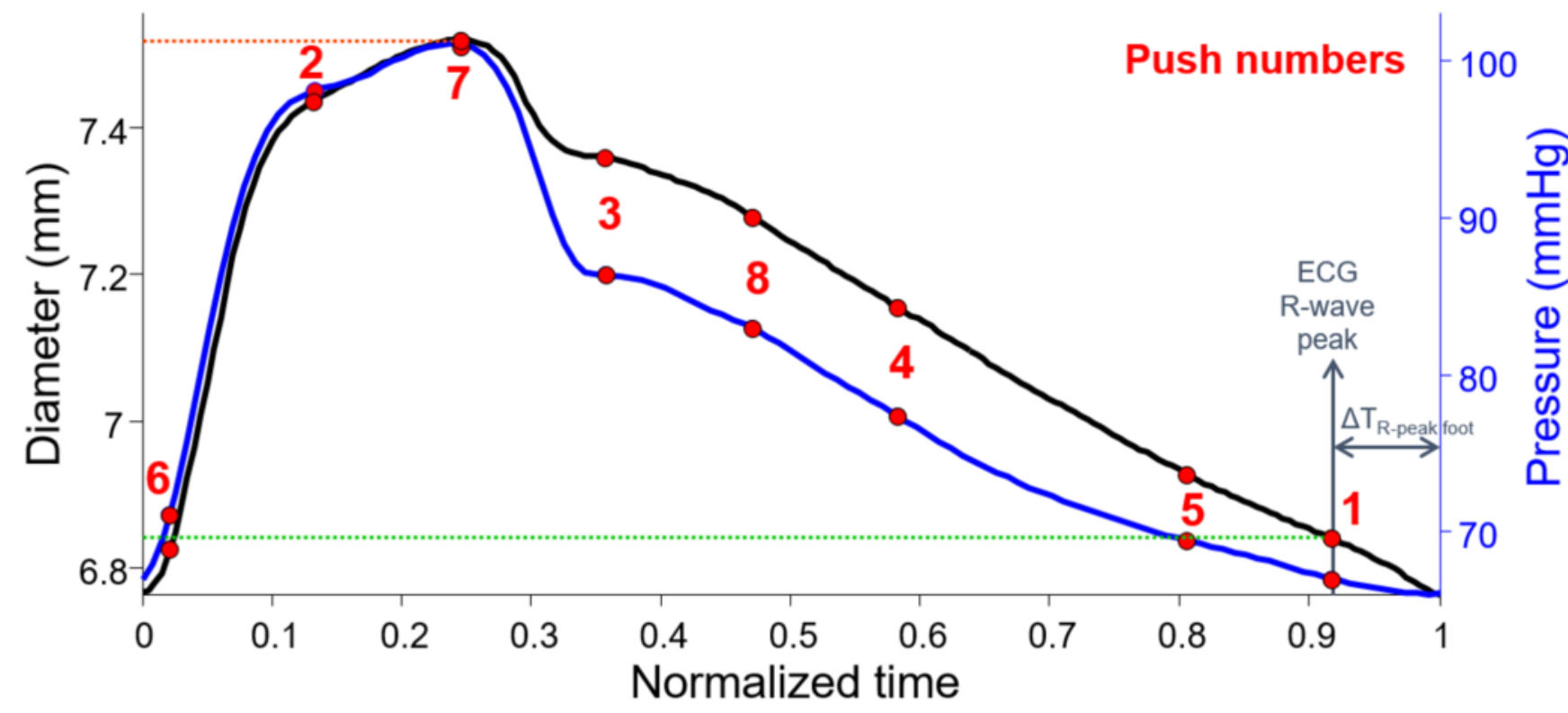

c. IQ images for two pushes with 5 position lines covering each wall thickness

Push 1

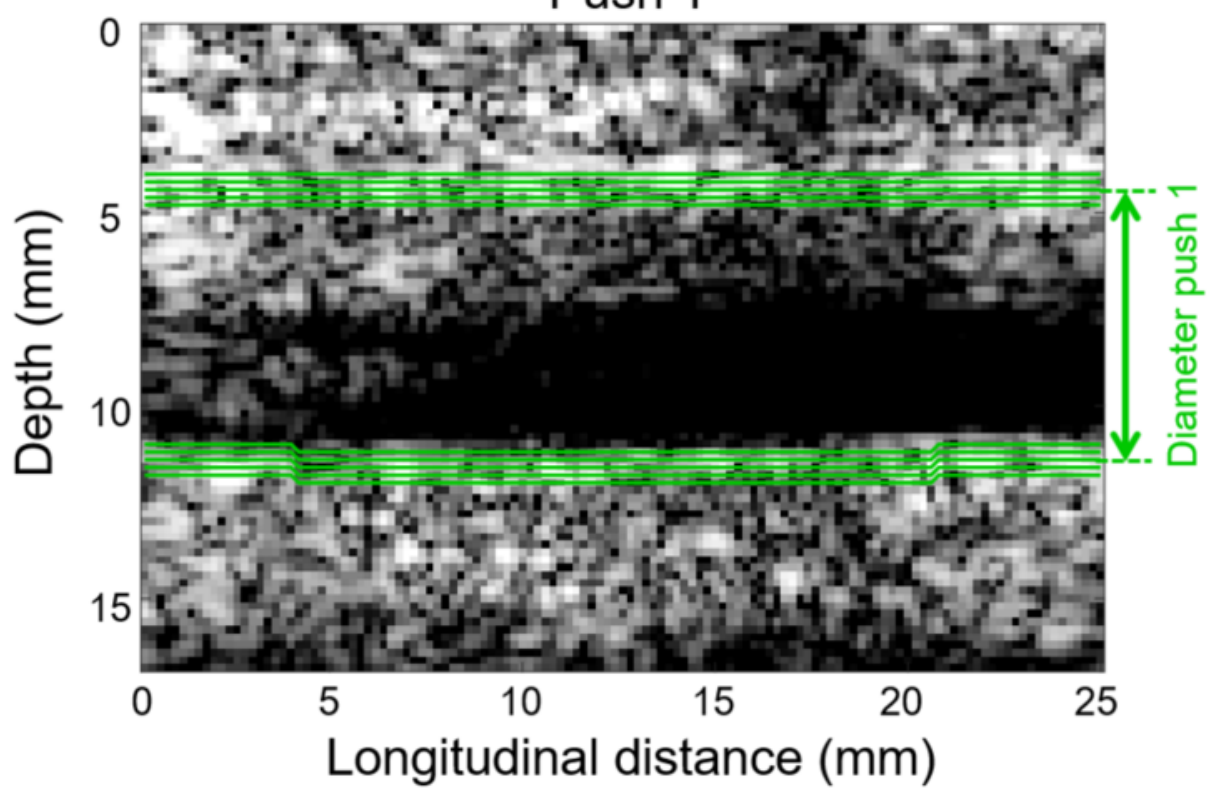

Push 7

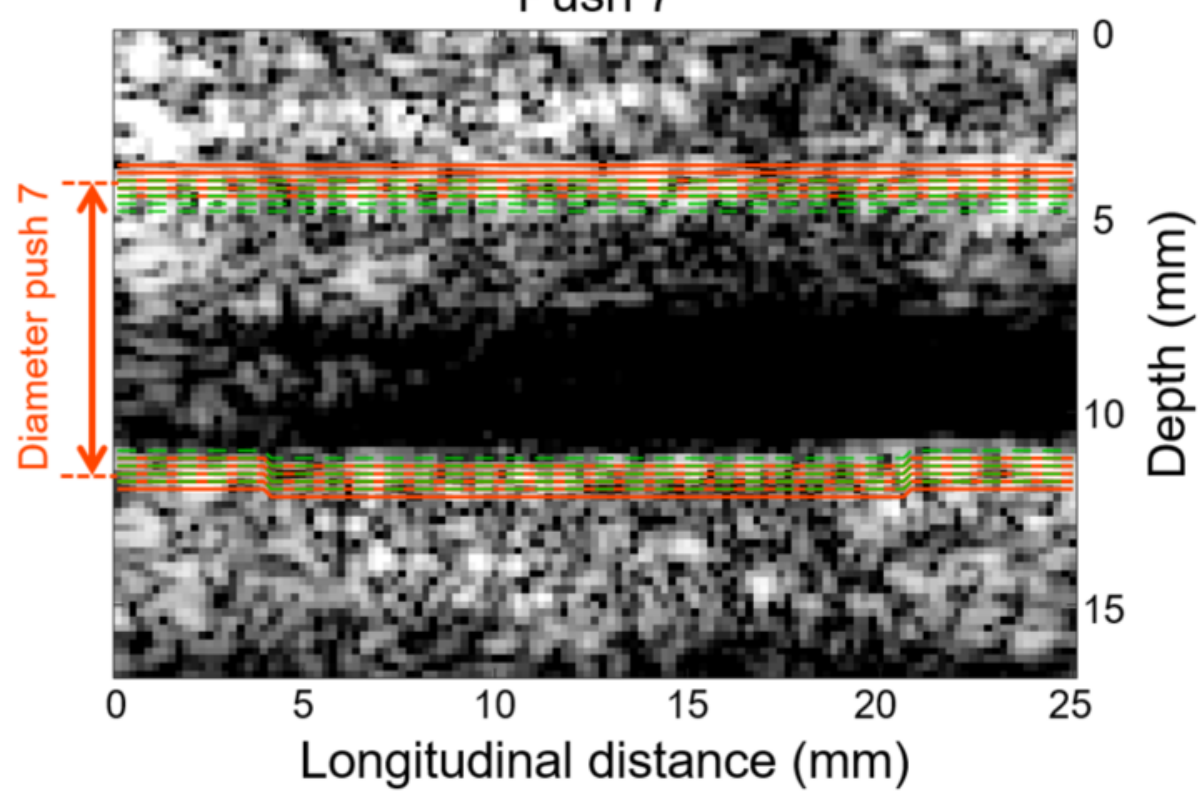

d. Spatiotemporal wall velocity maps and SWS assessment using Radon transform Anterior wall
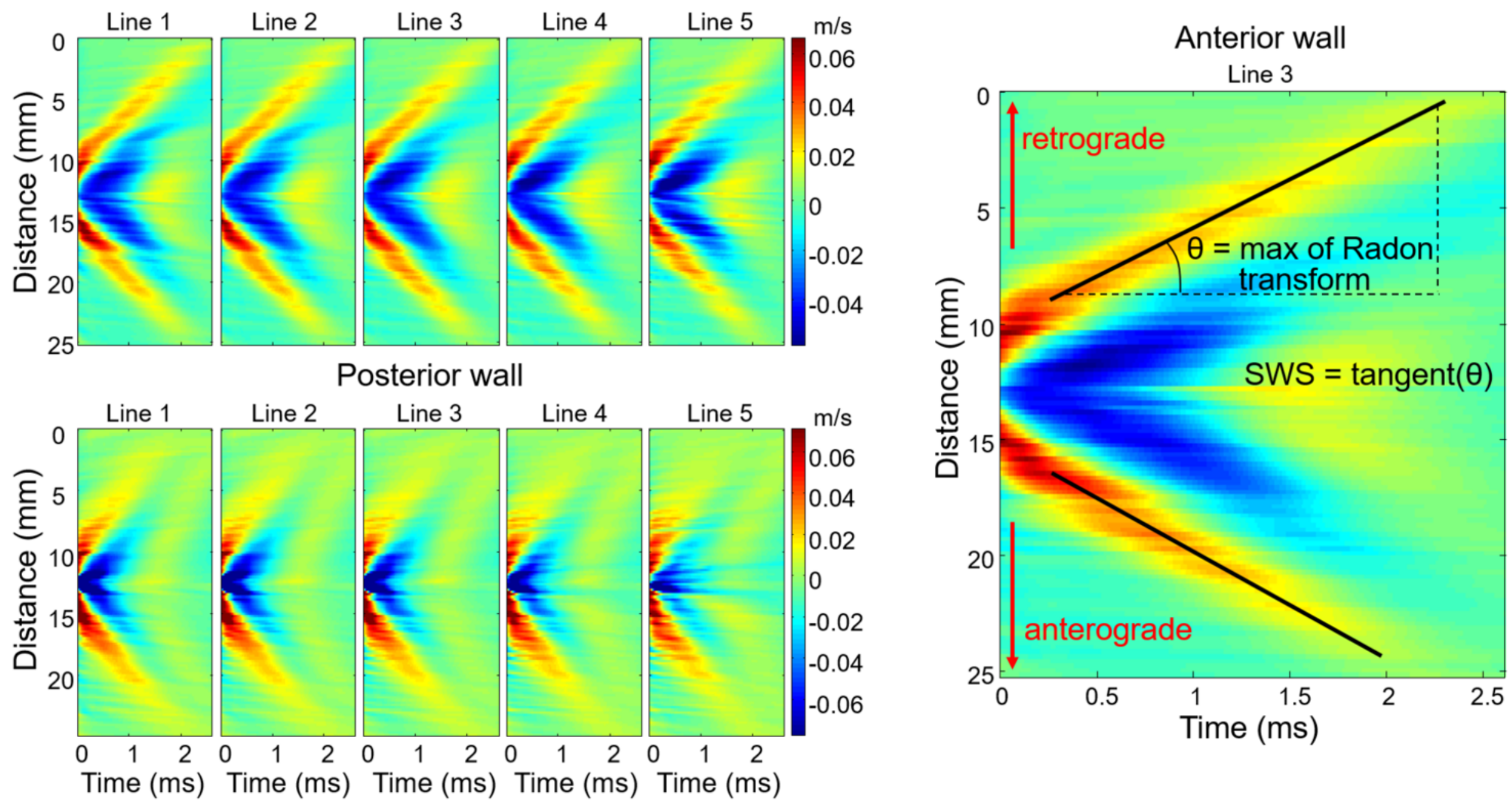
a

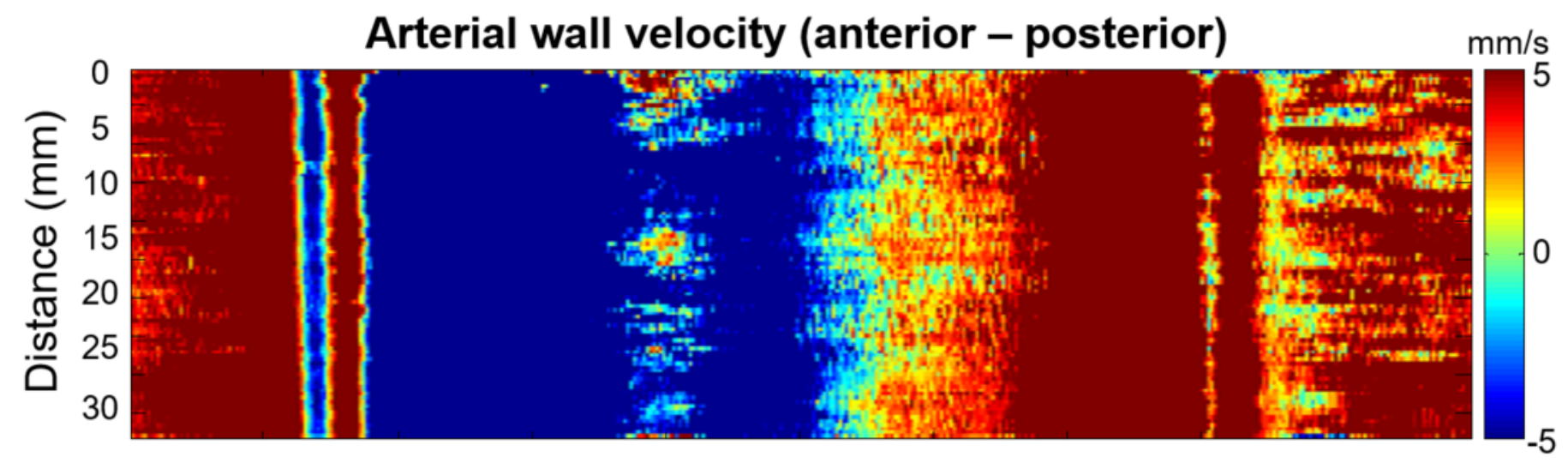

b

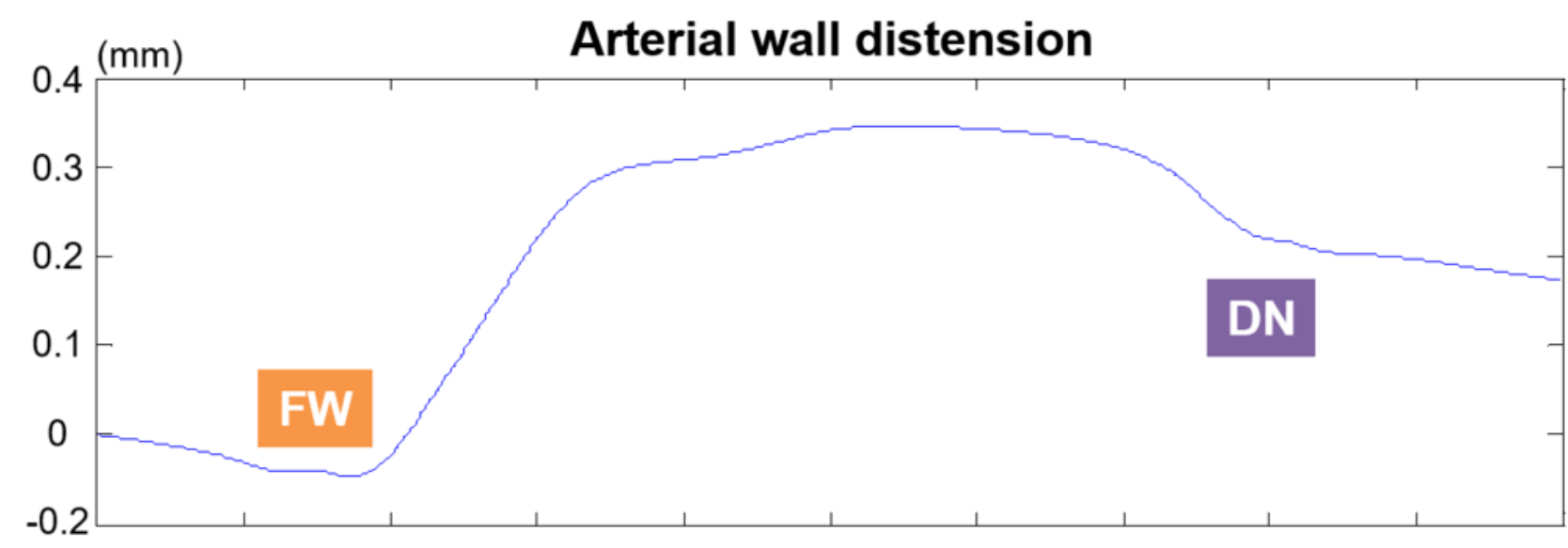

C

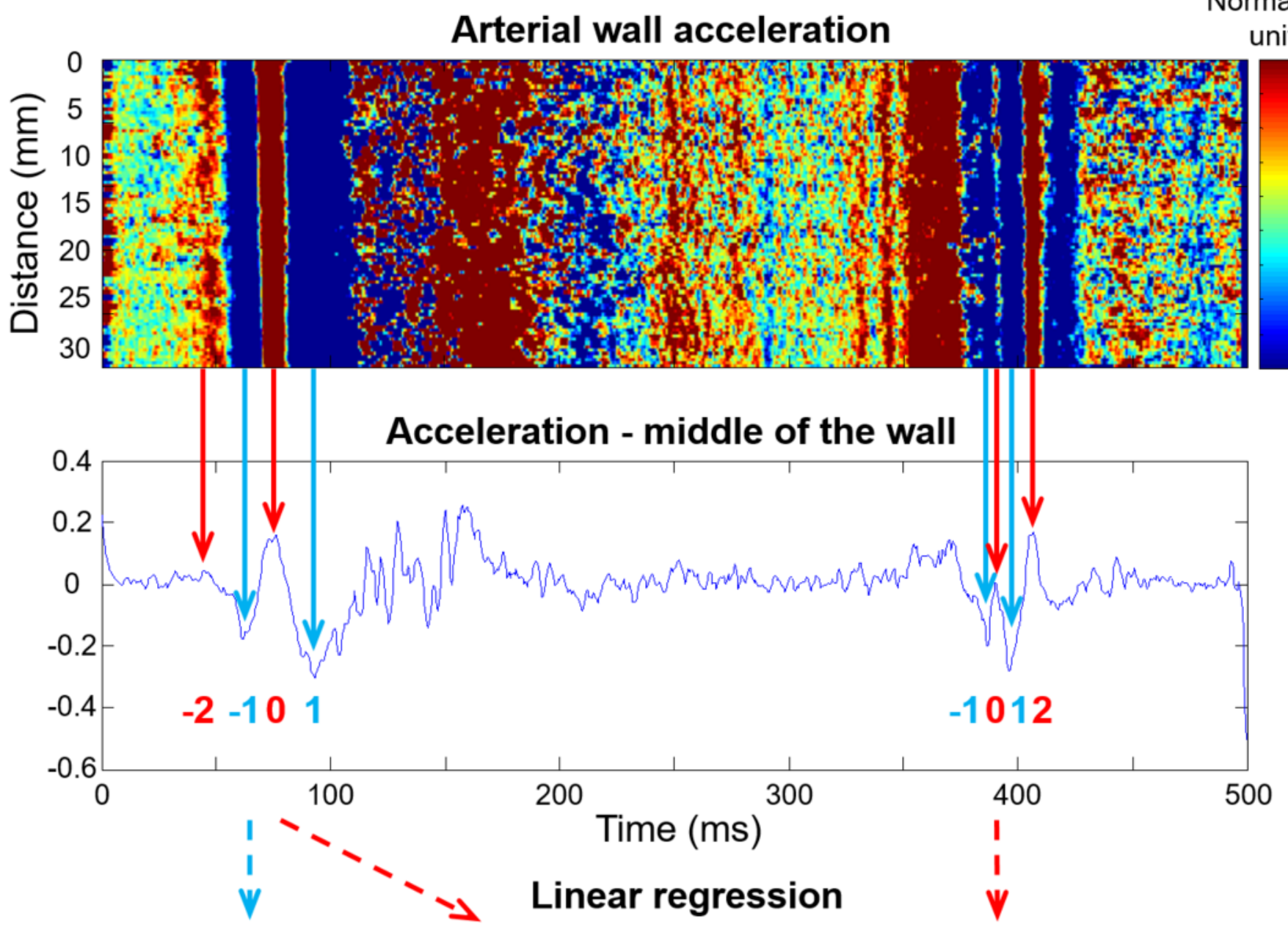

e

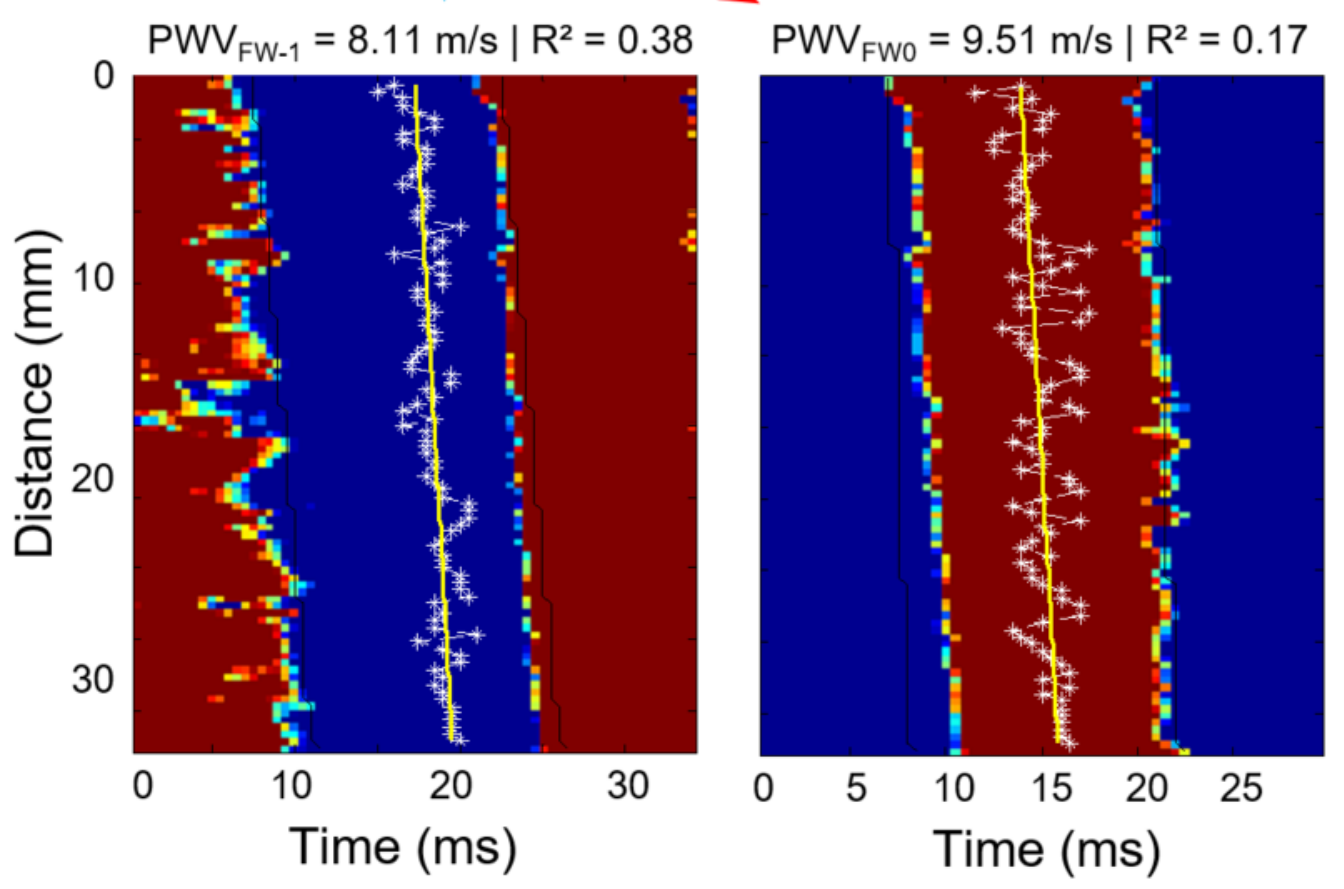

$\mathrm{PWV}_{\mathrm{DN} 0}=6.98 \mathrm{~m} / \mathrm{s} \mid \mathrm{R}^{2}=0.68$

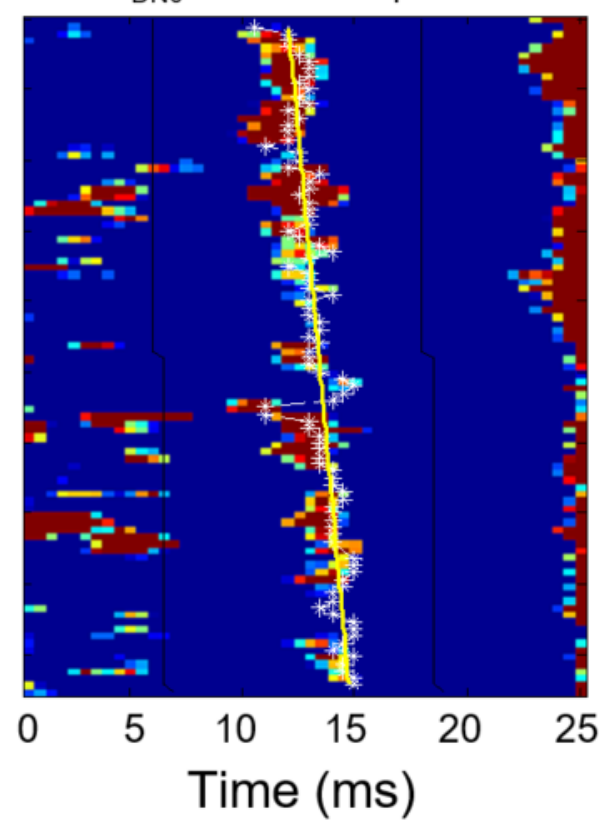

d 

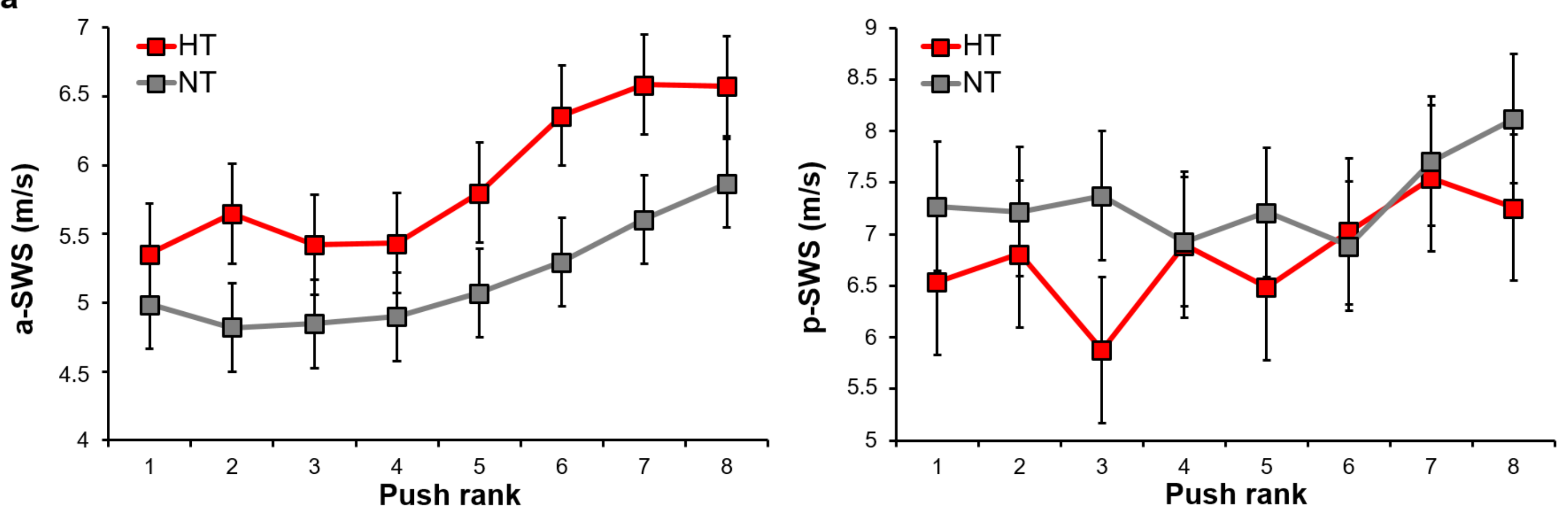

b

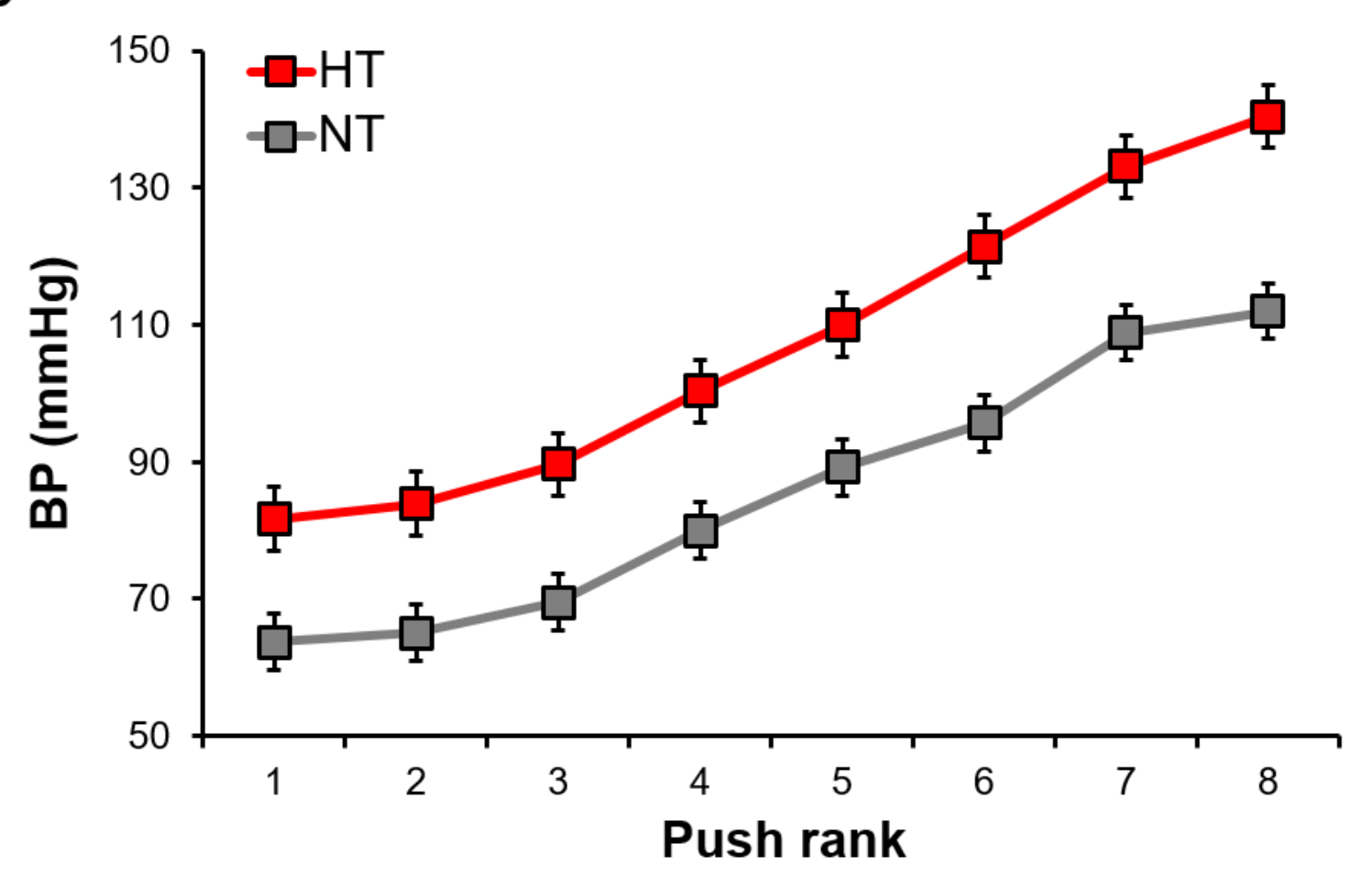

C
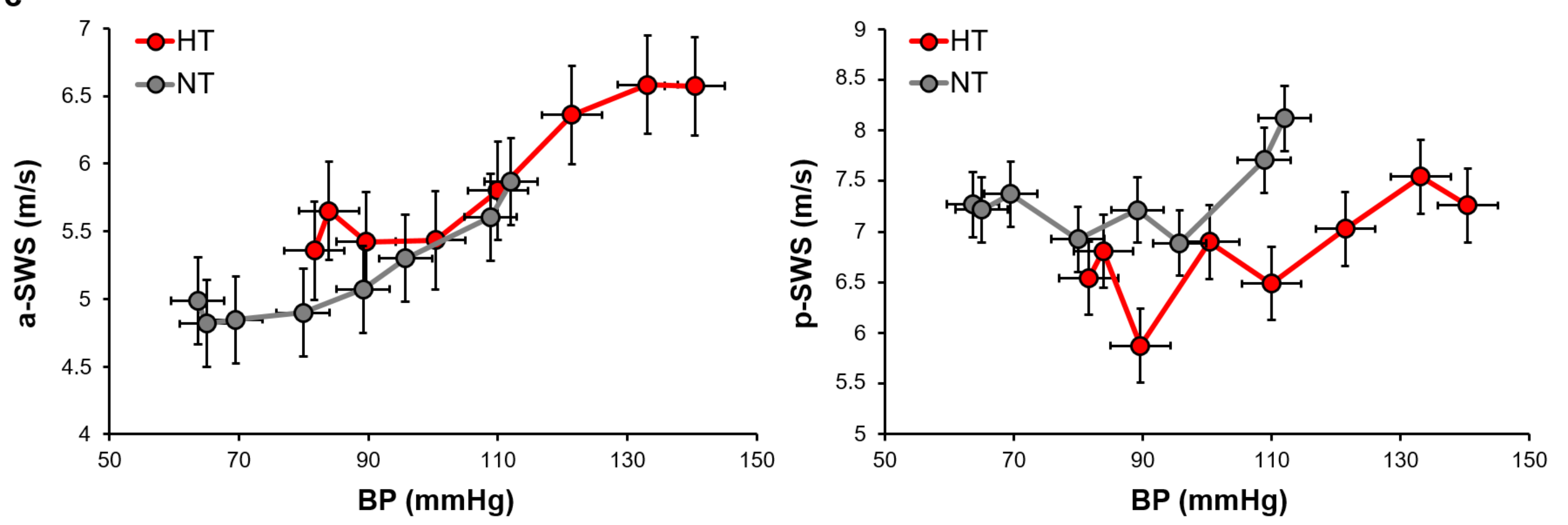